\title{
Mathematics Tools and its Efficiency on the Building's Environmental Performance
}

\author{
${ }^{1}$ Eng. Aya M. El-Bahrawy ${ }^{*}{ }^{2}$ Prof. Randa Reda Kamel, ${ }^{3}$ Ass. Prof. Inas Abd-Elsabour Ahmed \\ 1,2,3 Helwan University, Faculty of Engineering, Architecture Department
}

\begin{abstract}
Recently, mathematics has a wide influence on architectural design and performance. It can effectively help in solving design problems and promoting geometrical shapes efficiency. Consequently, the environmental performance has also widely developed with the involving of advanced mathematical branches and computational software. The main aim of the paper is to study the importance of using mathematics in raising the building's environmental performance. Therefore, the research methodology starts by clarifying the mathematics' branches and their application in architecture, then carries out an analysis for different case studies that used mathematics effectively in developing environmental performance. And lastly, apply one of the mathematical optimization techniques on a virtual prototype to illustrate how mathematics can effectively promote the building's environmental efficiency.
\end{abstract}

Keywords Mathematics, Geometry, Parametric, Algorithm, Topology, Environmental Performance.

\section{Introduction}

From ages, Architecture and mathematics had common basics and concepts. In history, architects were mathematicians and some mathematicians were architects too. Thus, architects had used mathematics by means of a tool in the developing of architecture projects, for example, the mathematical readings of Pythagoras that were used in building proportions [1]. Accordingly, that continued all overages till now in contemporary architecture where mathematics became a central core in the architecture from the initial stage of form-finding, shaping and generating complex forms to the fabrication process, via opening new horizons in architecture field [2].

In architectural design, Architecture Performance was a generic term that implies the ability to perform [3]. So, its evaluation criteria were multidisciplinary, thus some architects sorted architecture performance into environmental, structural, and social performance [4]. Environmental performance; which was selected in this research, that related to the built environment's quality, whether indoor or outdoor, Structural performance; that cares directly about occupants' safety in the buildings. While, Aesthetic performance; affected by form, material selection, and, color [3].

\footnotetext{
${ }^{*}$ Corresponding author: Assistant Lecturer, Faculty of Engineering, Helwan University

E-mail: aya_mahmoudfawzy@m-eng.helwan.edu.eg
} 


\subsection{Research Problem}

Mathematics has revealed a wide range of methods and techniques with high potential in promoting environmental performance efficiency. Therefore, the nonawareness of these techniques can make architects miss several chances in optimizing the building's environmental performance and solving many of the environmental problems that appear within the designing stage.

\subsection{Research Aims}

The study aims to analyse and measure the connection between mathematics and environmental architecture performance by:

- Illustrating mathematical branches and identifying their application in architecture.

- Clarifying environmental performance concept and evaluation criteria.

- Prove that mathematics has a vital role in promoting the building's environmental performance.

\subsection{Research Methodology}

For attaining the research aims, the methodology was divided into three parts; First, clarify mathematics different fields and their application in architecture, along with identifying environmental performance concepts and its evaluation criteria. Second, analyse several architectural projects that effectively optimize their environmental performance by using mathematics to investigate to what extent the mathematical fields could promote the environmental performance. Third, apply one of the mathematical optimization techniques on a virtual prototype to environmentally optimize its efficiency and simulate its environmental performance to validate the mathematics capability in improving environmental performance.

\section{Mathematics in Architecture.}

\subsection{Historical Review}

Mathematics has always existed in creating art and architecture throughout history. By starting with geometry, it's roots could be seen in Egyptian, Babylonian, and Hindu old civilizations [5]. As a result, geometry's types could represent entire periods in architecture as; Euclidean geometry from Antiquity to the Romanesque period, Perspective and Projective geometry from the Gothic and Renaissance period to the Neo-classical eras, and non-Euclidean geometries for modern architecture [6].

Whereas, in the digital era with the integration between mathematics and computer techniques, new mathematical tools have renovated with more architectural benefits, rather than just being for modelling and presenting, it had a main role in form-finding, shaping, generating of forms, as in parametric and algorithmic generation, and topological formations. Subsequently, it opened new horizons for mathematical and geometrical contribution in architecture, [2,7].

\subsection{Mathematical Branches}

There were several mathematical branches that helped in forming architecture. The paper will discuss four of the commonly used branches, which are; Geometry, Parametric, Algorithm, and Topology. Table 1 shows the differences between previous branches and their application in architecture. 
Table 1 Types of Mathematics in Architecture MATHEMATICS TYPES

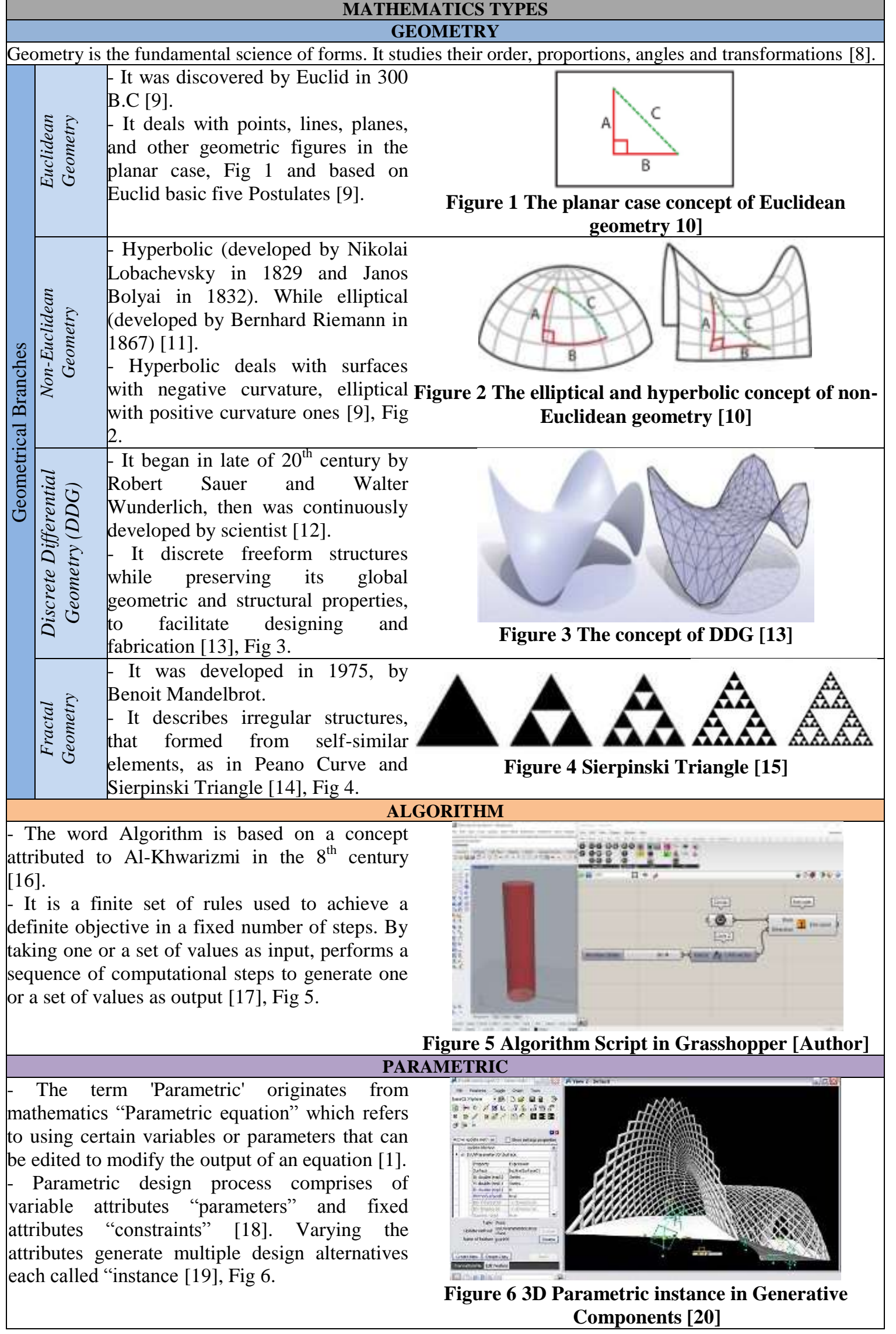


- The first appearance of topological approach in architecture was in Greg Lynn essay "Folding in Architecture" in 1993, inspired by Gilles Deleuze's philosophical theory "fold" [21].

- It is the transformations of one object to another, without cutting or splicing, while maintaining its topological identity [9], Fig 7.

\section{TOPOLOGY}

\section{Environmental Performance.}

Environmental performance is one of the main categories in architecture performance, as being performative is usually related to sustainability and environmental behaviour of buildings [23].

\subsection{Environmental Performance Evaluation Criteria}

Environmental performance criteria could be classified in to two main sections; functionality and efficiency, each section has sub-categories [24]. Table 2 illustrates each of them in detail.

Table 2 Environmental Performance Evaluation Criteria ${ }^{\text {[24, 25, 26, 27, Author] }}$



\subsection{Environmental Performance Computational Simulations}

Recently, building performance simulations (BPS) became an integral part in designing and evaluating building's environmental performance. So, they enabled designers to simulate and quantify the impacts of various design strategies that affect building environmental performance early in the design process. By analysing different environmental criteria as; energy consumption, daylighting, natural ventilation, or solar radiation [19]. Table 3 shows a few of the commonly used environmental simulation Software: 
Table 3 Examples of Environmental Analysis Software and Tools

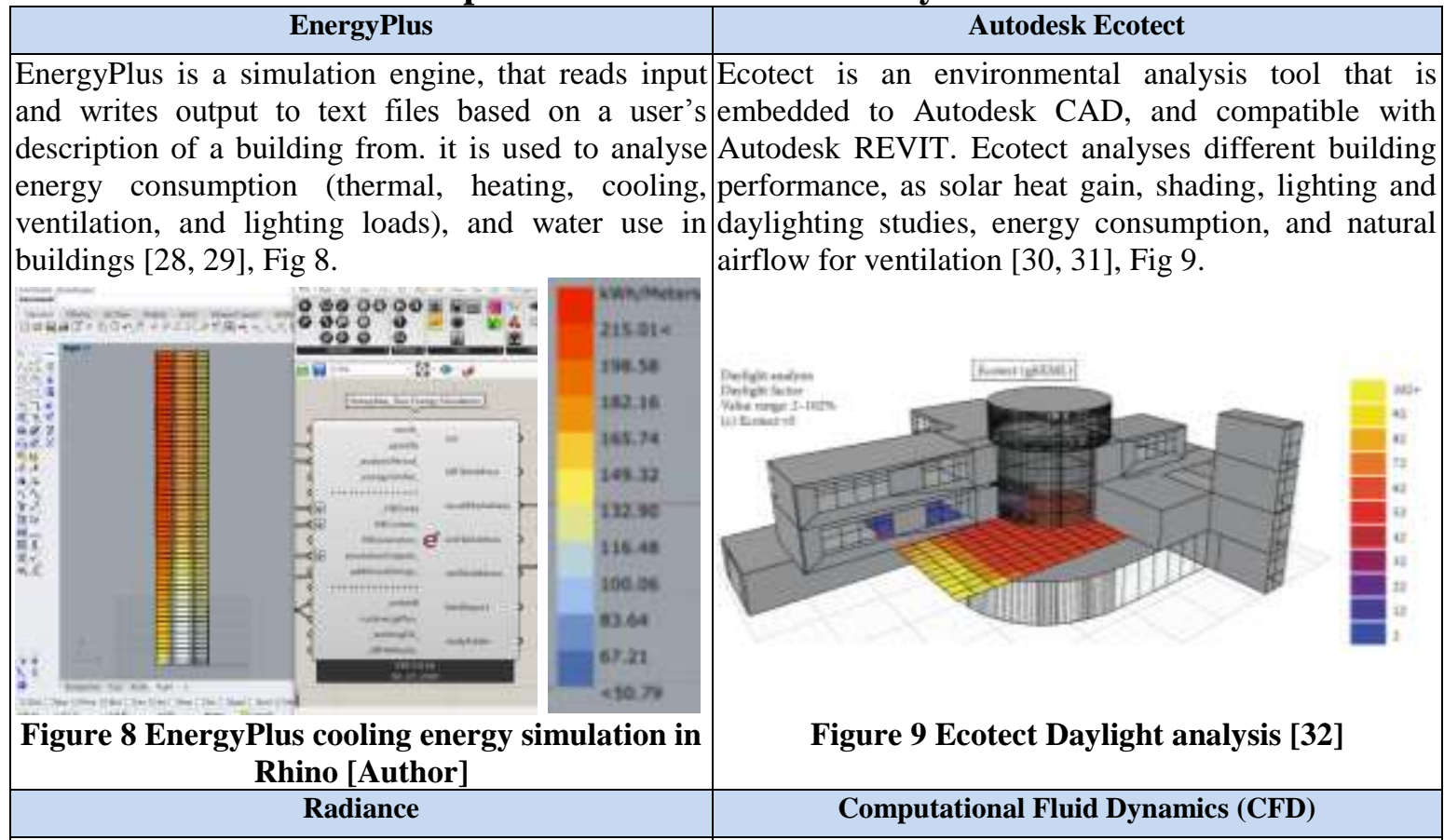

Radiance is an analysis tool that uses input files to CFD is a tool that uses algorithms and numerical specify the geometry as materials, luminaires, time, methods to solve and analyses mass, momentum, date and sky conditions, to analyse daylighting, thermal energy, natural ventilation design, building illumination, visual quality, spectral radiance, material emissions, complex flows of fire and smoke, irradiance and glare indices [33], Fig 10.

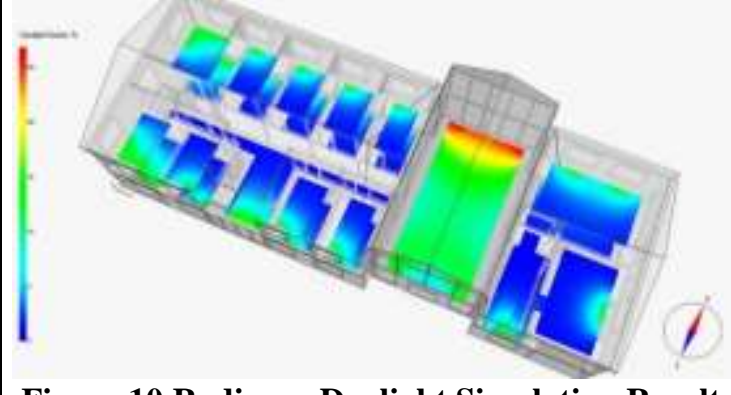

Figure 10 Radiance Daylight Simulation Results [34] and predictions of noise [35], Fig 11.

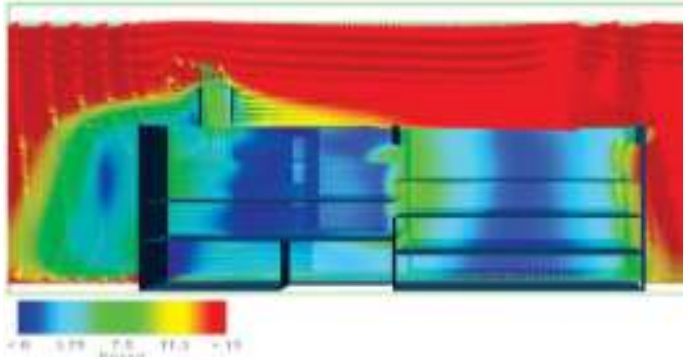

Figure 11 CFD Simulation and Analysis Model [35]

Insight 360 and Sefaira are plugins for Revit. Sefaira They are both open-source plugins for Grasshopper is used in performing energy and daylight analysis. and Rhino. Honeybee can perform energy, daylight, While, Insight 360 is used in performing energy, natural ventilation, and heat transfer analysis. While, solar radiation, and lighting analysis [19], Fig 12

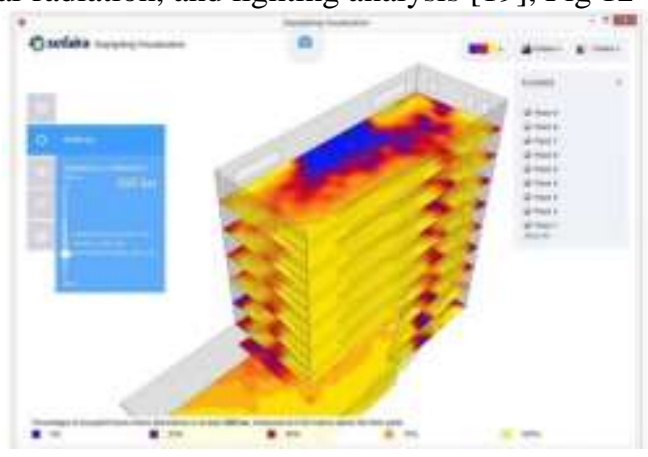

Figure 12 Sefaira Daylight Analysis [36]
Ladybug performs sun path, shadow range, solar radiation, outdoor comfort, and wind roses analysis [19], Fig 13.

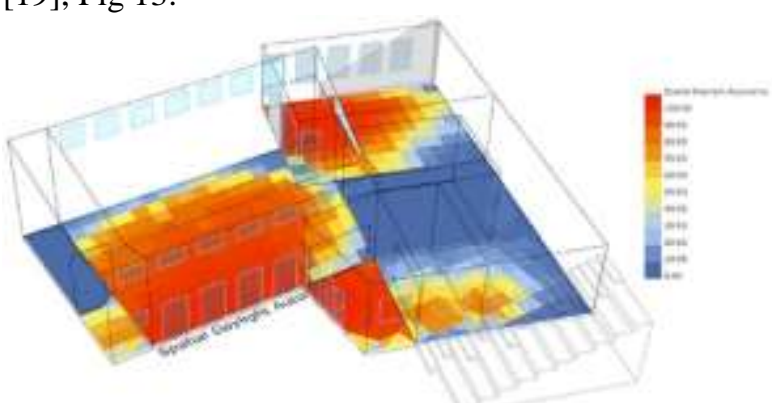

Figure 13 Honeybee Daylight Analysis [37] 


\section{Mathematics, Architecture and Environmental Performance.}

Mathematics and architecture have always been related; the both roots are embedded in geometry. Architecture has been concerned with the creation of space; mathematics with its description and definition. In architecture, mathematical rules and techniques were used to offer solutions to the problems of defining and building free-form surfaces [9].

In the last two and half decades, Digital computation has given architects new creative opportunities to creatively design and optimize geometrical space, that was opened up by mathematics. In general, mathematical computation techniques are used in a verity of ways to solve spaces problems or optimize their performance, as structural optimization as resolving the panelization of surface, or environmental as resolve the space's acoustic efficiency [9].

The following part of the research will discuss the relationship between each branch of mathematics and architecture in detail and their role in promoting building environmental performance.

\subsection{Geometry}

Geometry has an important role in developing architectural forms and spaces, as it studies the environmental, aesthetical and structural characteristics of the geometrical figures and shapes. In addition to, their proportions, angles, relations, differences, and transformations. Accordingly, geometry can facilitate selecting the shapes in initial design phase and indicate which have the higher performance, and help in developing these shapes to further promote building environmental performance, as creating suitable spaces for the required functions, optimizing material distribution, and reduce energy consumption, and material usage $[1,14]$. That can appear clearly in the following two examples, Table 4.

\section{Table 4 Geometry Application in Promoting Environmental Performance}

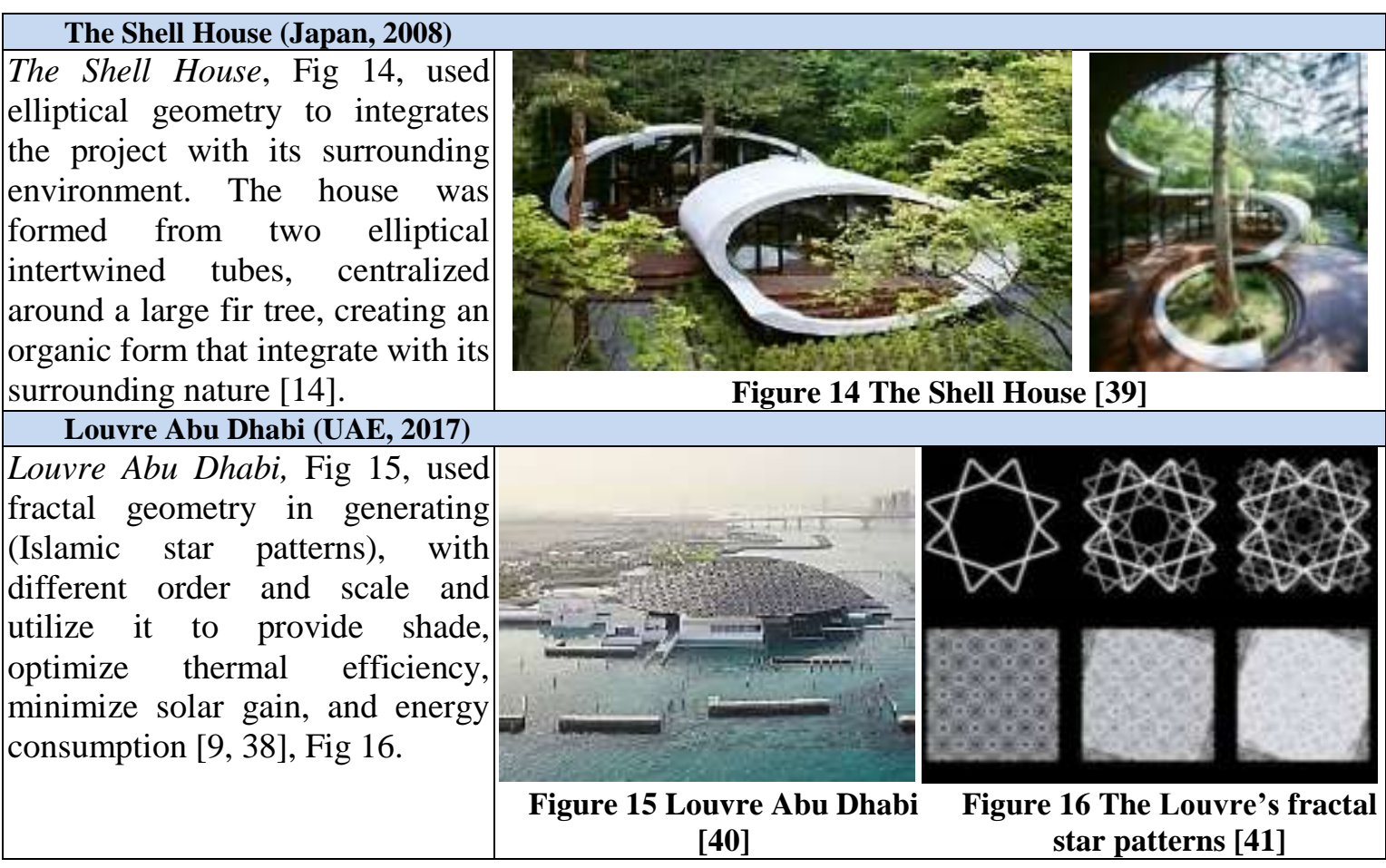


In architecture, Geometry importance locates in its ability in developing geometrical forms and patterns by utilizing the form's characteristics, properties, proportions, order, scale and transformation to promote building's environmental performance efficiency.

\subsection{Algorithm}

Algorithmic design or Generative design, is a programming-based design approach [42], allows designers to script the design process in a set of instructions, as environmental or functional requirements, then generate, evaluate and filter the outputs to chooses the optimal solution from a set of generated alternatives $[9,11]$. Algorithmic Generative design concept can be clarified in two of its techniques; LSystem and Genetic Algorithms (GA).

L-system, is an algorithmic generative technique that produce fractal's structure describes the growth process and structure characteristics of plants and natural forms $[43,44]$.

Genetic Algorithm is an evolutionary algorithm resembles the biological evolution processes, in which the best characteristics are continuously selected and transferred to the next generations, so at the end of the process, the last generated forms will have the best characteristics [46].

The two techniques concepts can be cleared in the following two case studies, L-system in The Tote Restaurant and Genetic Algorithm in Alibaba's Shanghai offices, Table 5.

\section{Table 5 Algorithm Application in Promoting Environmental Performance}

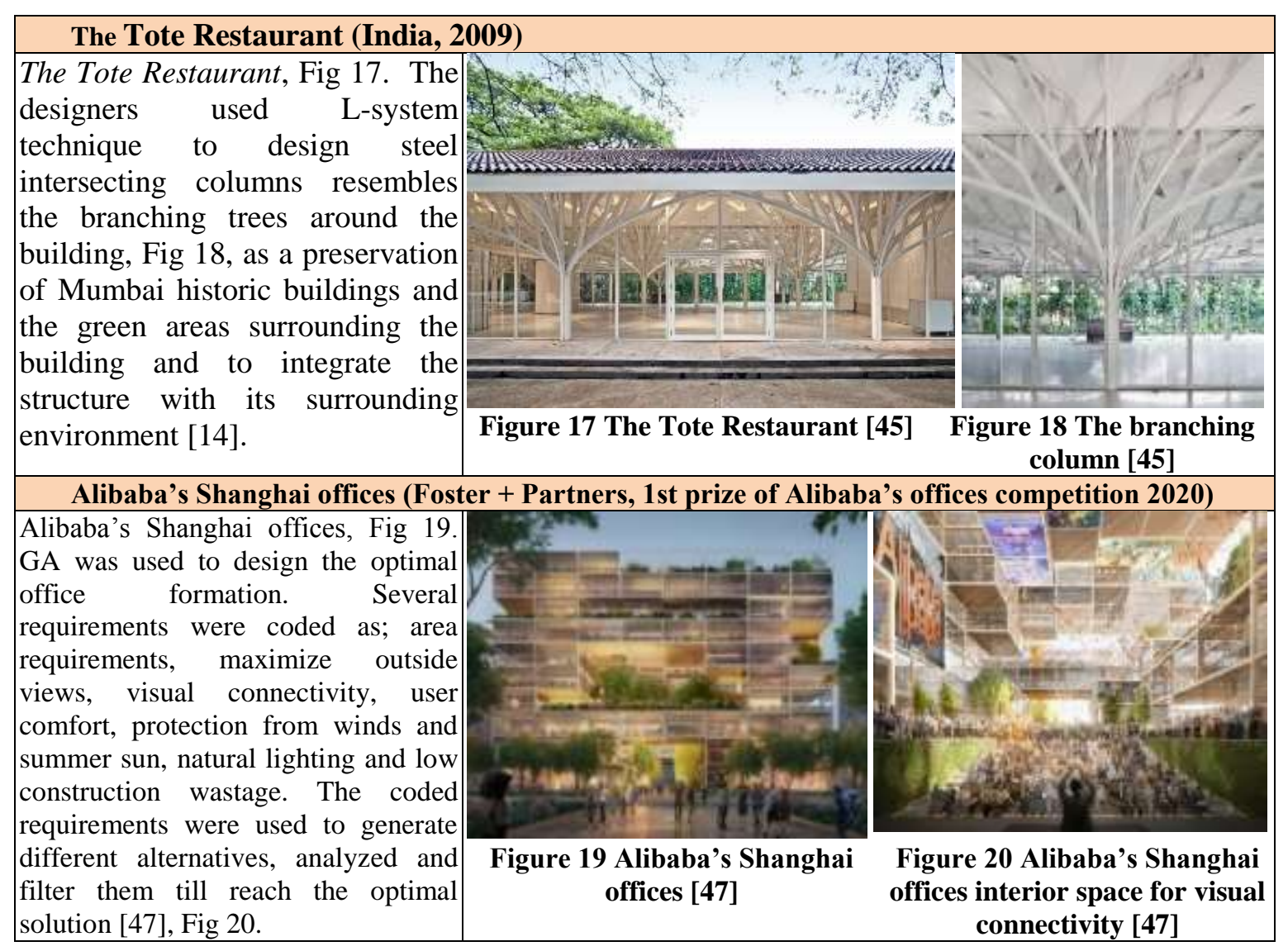


In architecture, Algorithm capability locates in coding building's requirements whether environmental or structural requirements, then generate and evaluate, and filter multiple design solution in continuous cycle till reach the most performative solution.

\subsection{Parametric}

Parametric is a computational generative and analytical method [17], that use variable and fixed parameters to generate multiple design alternatives each by changing these parameters [18, 19]. Parametric design can model and generate complex architectural forms with few parameters, as environmental or functional requirements [48]. In addition, Parametric design has the ability to integrate with Building Performance Simulations (BPS) and Evolutionary Optimization Algorithms to increase its capacity to orient the design process to the optimal performative solution $[19,49]$. Parametric capabilities can be seen in the following examples, Table 6

\section{Table 6 Parametric Application in Promoting Environmental Performance}

\begin{tabular}{|c|c|}
\hline Aviva Stadium (Ireland, 2010) & \\
\hline $\begin{array}{l}\text { Aviva Stadium, Fig } 21 \text {, used a single } \\
\text { parametric model to design the } \\
\text { overall geometrical form. Parametric } \\
\text { design had analyzed and tested the } \\
\text { position, rotation values and opening } \\
\text { angle of the façade panels to provide } \\
\text { natural air ventilation, remove hot air } \\
\text { behind the panels, and minimizing the } \\
\text { effect of windblown rain, and } \\
\text { optimize building environmental } \\
\text { performance }[17,50] \text {, Fig } 22 \text {. }\end{array}$ & 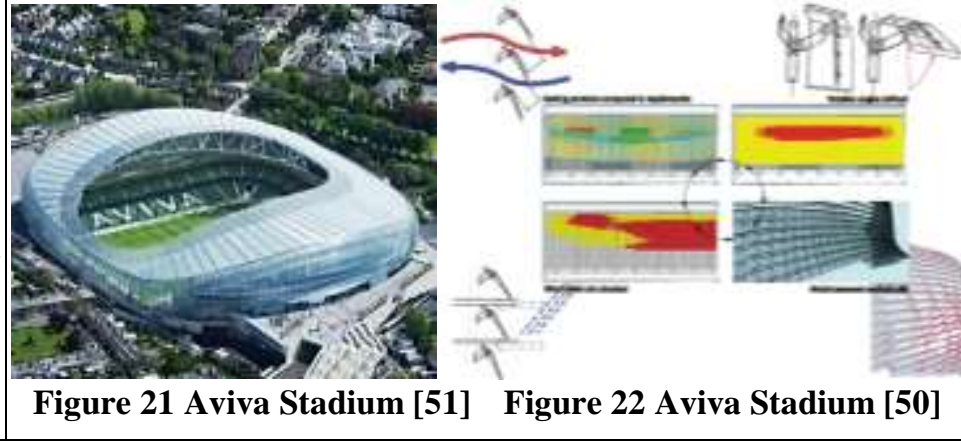 \\
\hline CITIC Tower (China, 2018) & \\
\hline $\begin{array}{l}\text { CITIC Tower, Fig 23, used } \\
\text { parametric framework to reach the } \\
\text { optimal balance between design } \\
\text { formation, functional efficiency and } \\
\text { structural performance. Several } \\
\text { design alternatives were generated, in } \\
\text { the initial design stage, with different } \\
\text { waist heights, planar sizes, and } \\
\text { functional zonings. The alternatives } \\
\text { were analysed and compared } \\
\text { continuously till achieve optimal } \\
\text { aesthetical and structural } \\
\text { performance. Parametric design } \\
\text { helped in optimized floor usage } \\
\text { efficiency by providing more office } \\
\text { spaces at the higher levels, } \\
\text { comfortable working space, easy } \\
\text { access; and minimize walking } \\
\text { distance, Fig } 24 .[52,53,54,55] \text {. }\end{array}$ & $\mid \begin{array}{c}\begin{array}{c}\text { Figure 23 CITIC } \\
\text { Tower [55] }\end{array} \\
\text { Figure 24 the total parametric framework of } \\
\text { Analysis and Design Engine [55] }\end{array}$ \\
\hline
\end{tabular}

In architecture, Parametric design is a powerful tool that has the ability to model generate and simulate complex architectural forms based on the project's requirements as environmental criteria, early in the design process, to promote its building's efficiency. 
In addition, Parametric has the capability to integrate with genetic optimization algorithms that analyse the different generated alternative in continuous cycle till select the optimal alternative.

Further, it has ability to integrate with BPS that connect the conceptional model with external simulation software whether structural or environmental analysis software to simulate building's performance values under structural load or external environment to promote building performance efficiency within design stage.

\subsection{Topology}

Topology Optimization (TO) is an algorithmic-based approach that mimic the rules of biological growth in nature, to promote architecture performance. It utilizes optimization algorithms to find the optimal topological configurations that have the optimal structural efficiency, optimal material density and distribution, and least material usage and wasted energy, within a given design requirements [56]. Topology Optimization generates strong organic architectural forms with optimal structural response to applied loads, in a similar way as forms in nature [57]. Its techniques can be clarified in the following examples, Table 7.

\section{Table 7 Topology Application in Promoting Environmental Performance}

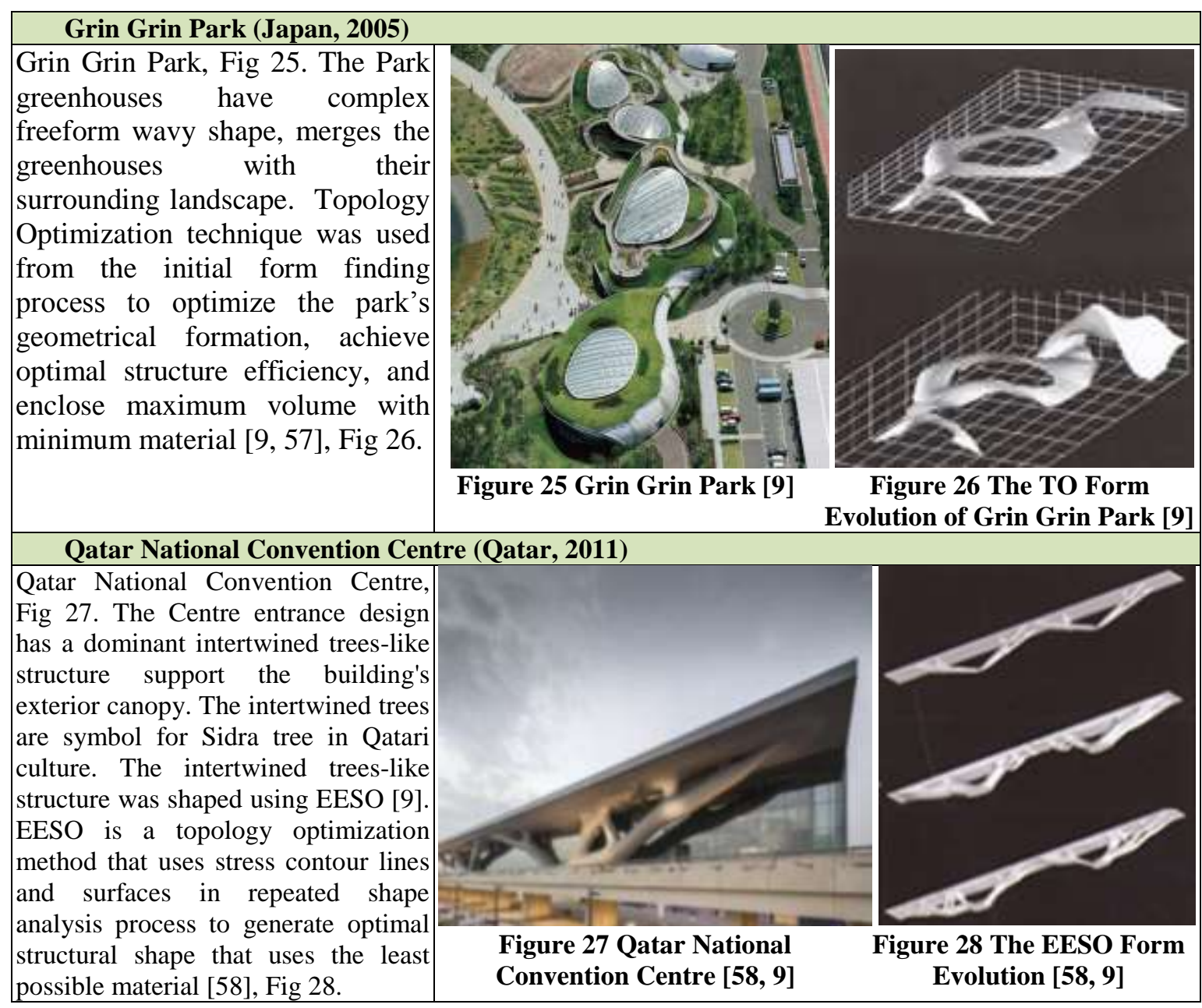


In architecture, Topology optimization is mainly use in shaping architectural forms to have the ideal topological configurations, the optimal structural efficiency, optimal material density and distribution, and least material usage and wasted energy. Thus, environmentally it mainly helps in decreasing material usage and wasted energy in construction process.

\section{Applied Study}

The applied study aims to clarify the effect of using mathematics early in the design process in promoting building's environmental performance.to

\subsection{The Methodology.}

Therefore, to accomplish the applied study goal, the study was parted into two processes;

- First, Generation process: an algorithmic generative function was used on a basic geometrical formation (a vertical square tower) to indicate its optimal deformation that minimizes the solar heat gain on its envelope to the lowest value. Thus, heat gain was chosen as it directly influences many environmental performances criteria as energy, thermal, and air efficiency.

- Second, Evaluation process: an energy, thermal, and air temperature simulation analysis were performed on both the basic and optimized formation to compare and verify the efficiency of the optimized solution.

The two processes were performed by using Rhino Software and Grasshopper, Ladybug, and Honeybee plugins.

\subsection{The Processes.}

\section{- First, Generation Process:}

The study started by a basic square geometrical form, as an office tower with 52 floors locates in Cairo- Egypt. So, to generate the optimized form number of steps were performed, as follows:

- The basic geometry design; originally the square tower was oriented by consider two sides faced north for promoting light and air efficiency. Then, the area of the lowest 10 floors were maximized to increase the tower's stability, Fig 29.

- The basic form solar radiation analysis; later, an annual solar radiation analysis was performed on the tower to indicate its solar heat gain coefficient, Fig 30.

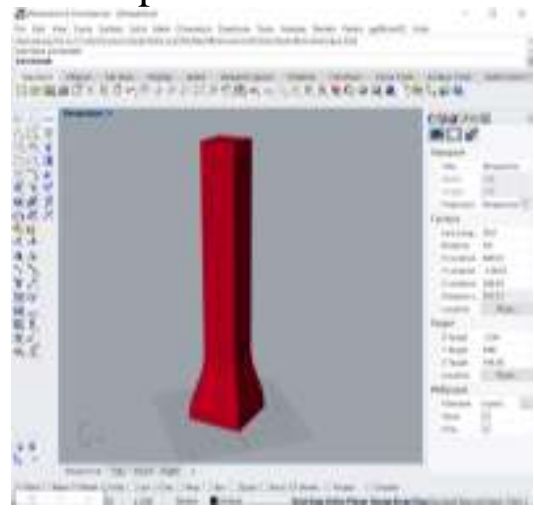

Figure 29 The basic geometry [Author]

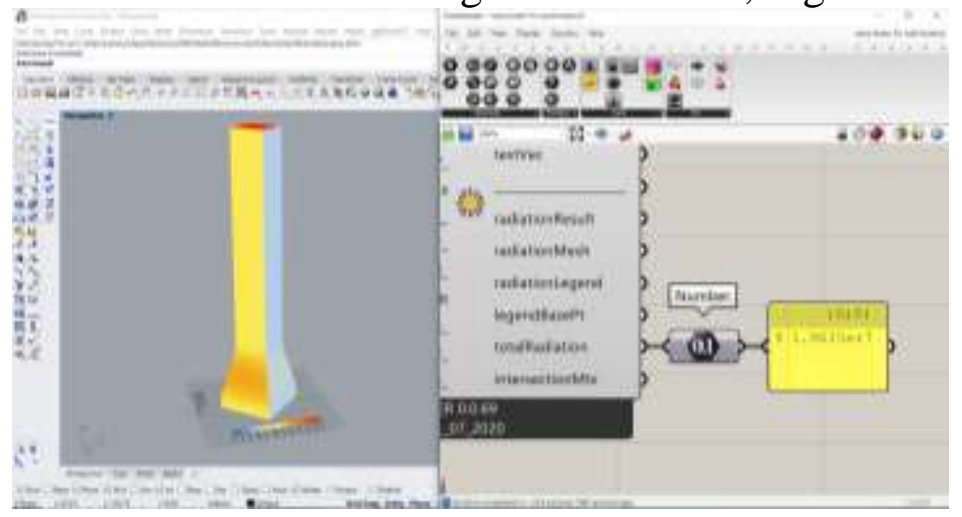

Figure 30 The solar heat gain value of the basic geometry: $1.9615 \mathrm{kWh}$ [Author] 
- Alternatives generation; next, an algorithmic generative component (Galapagos component) was used to generate different design alternative for the basic geometry with different rotation according to the lowest solar radiation value. It has generated 2601 alternative, evaluated, and filtered them to find the optimal solution.

- The optimal alternative; finally, Galapagos component showed that the optimal solution has $1.9447 \mathrm{kWh}$ solar radiation value and the lowest solar heat gain, Fig 31.

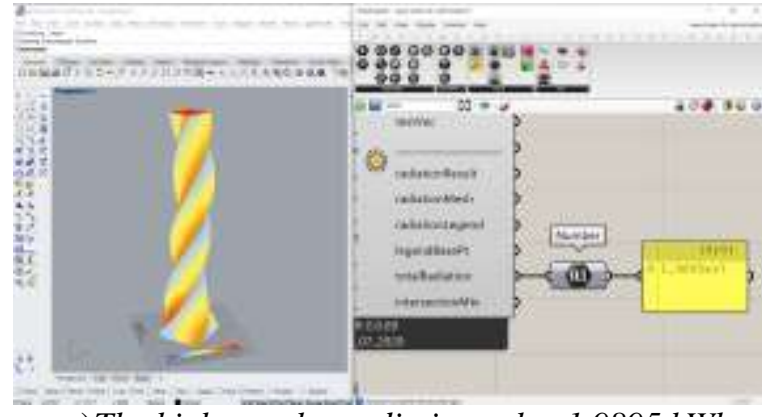

a) The highest solar radiation value $1.9895 \mathrm{kWh}$

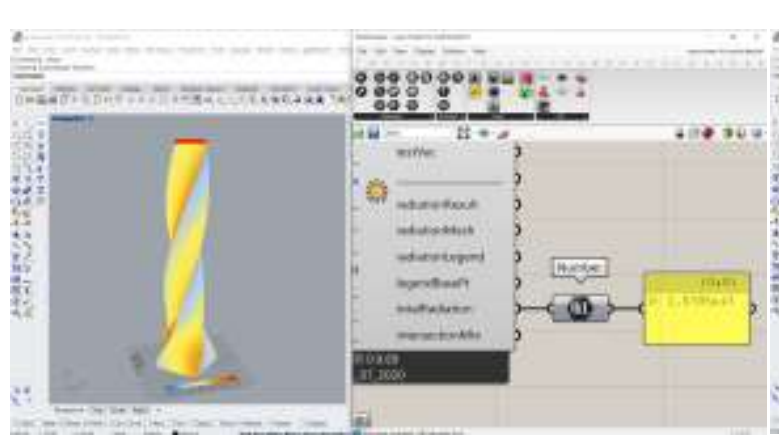

c)Design alternative with solar radiation value $1.9705 \mathrm{kWh}$

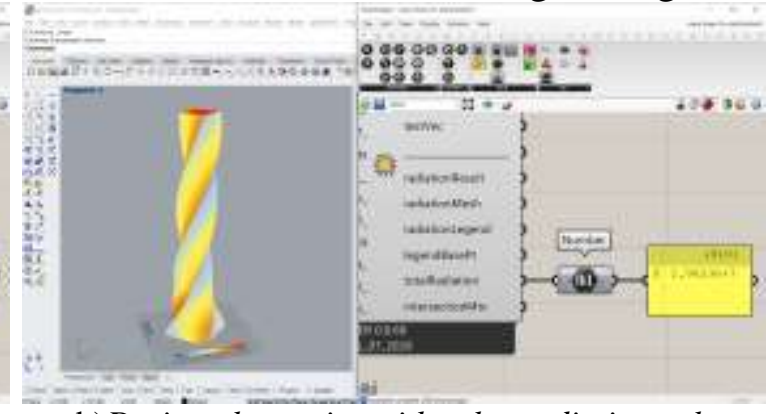

b)Design alternative with solar radiation value $1.9823 \mathrm{kWh}$

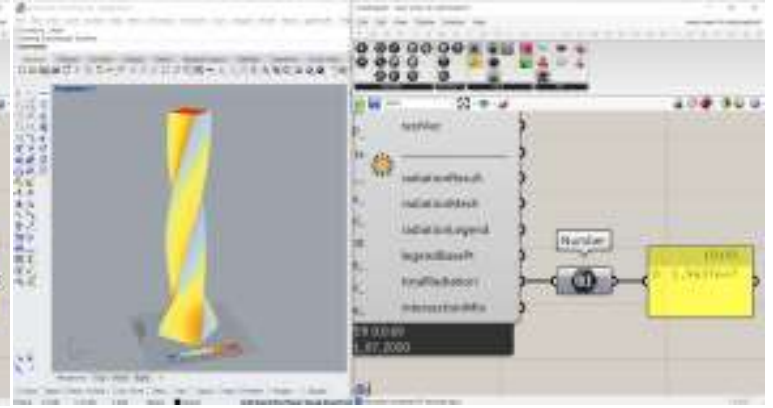

d)Design alternative with solar radiation value $1.9637 \mathrm{kWh}$

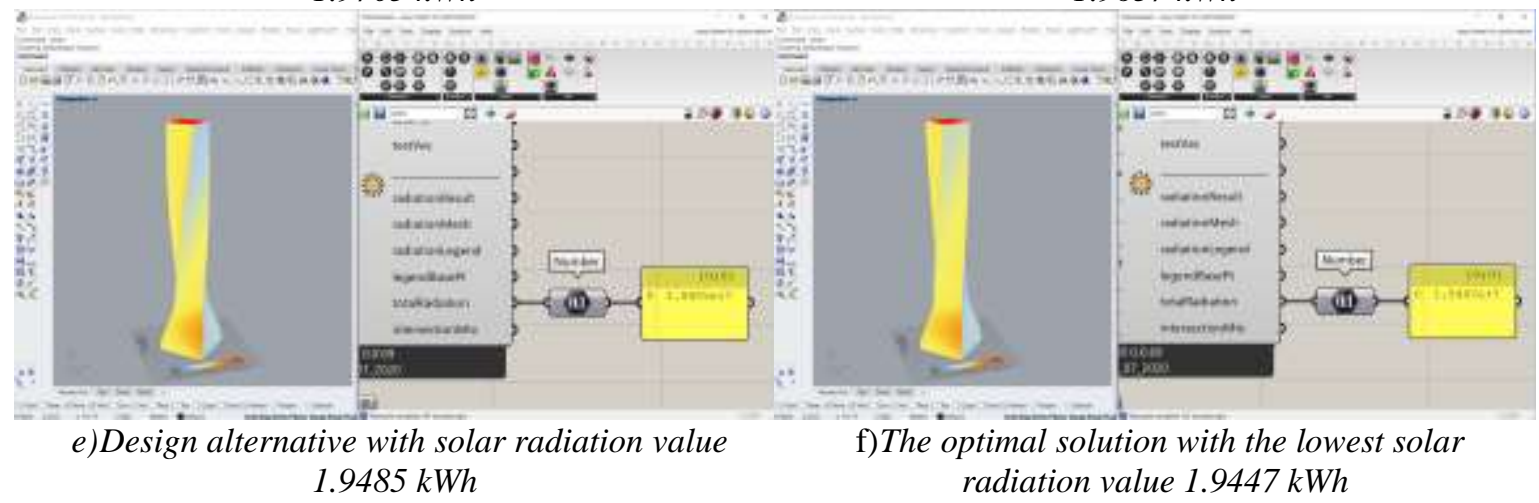

Figure 31 The solar radiation value of the different generated alternatives organized from the highest to the lowest value [Author]

\section{- Second, Evaluation process}

Consequently, before comparing the environmental performance of the basic and selected geometries, they were first adjusted to confirm the result accuracy. The both geometries were divided into 52 floors with central core, then cladded with glass panels where the glazing ratio is $0.75 \%$ in the overall geometry, Fig 32,33 . 


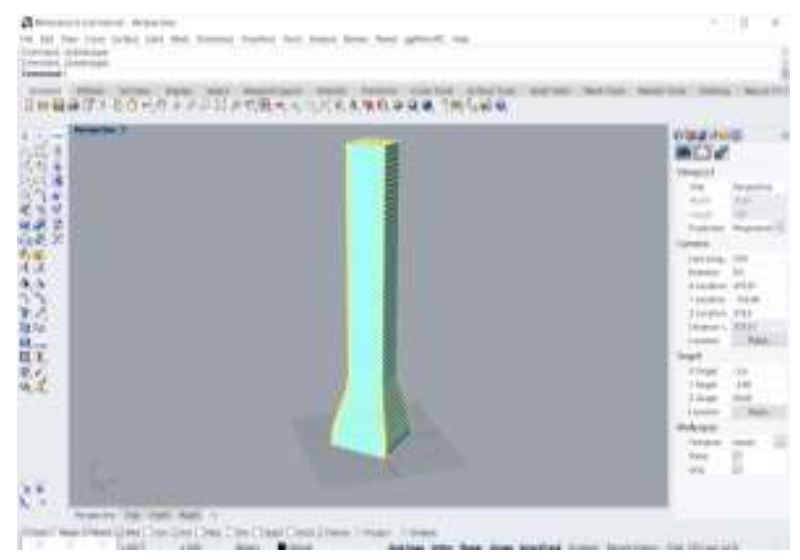

Figure 32 The main geometry [Author]

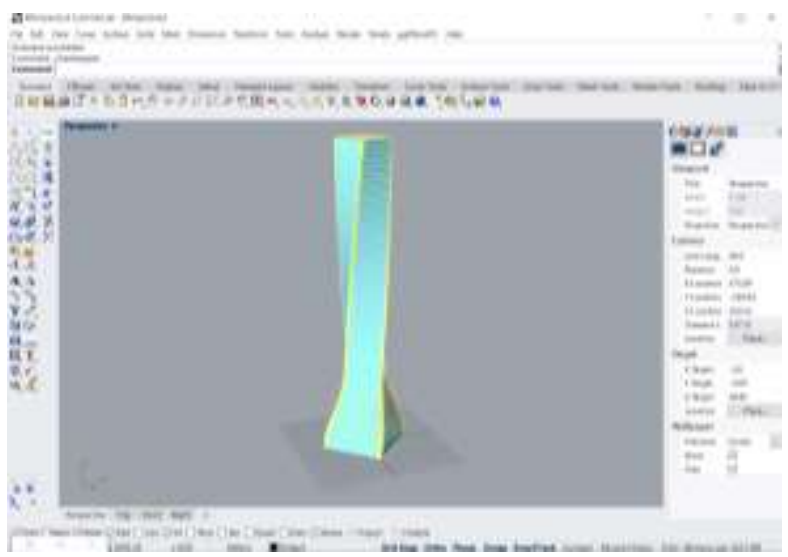

Figure 33 The optimized geometry [Author]

Thus, Table 4 shows a comparison between the environmental performance of the main and optimized geometry. The comparison started with comparing the two geometries' Solar Heat Gain, Fig 34, 35. Then, their Energy, Thermal, and Air Temperature simulations results to compare their performance, Fig 36 to Fig 45.

Table 4 Comparison Between the Environmental Performance of Main and Optimized Geometry [Author]

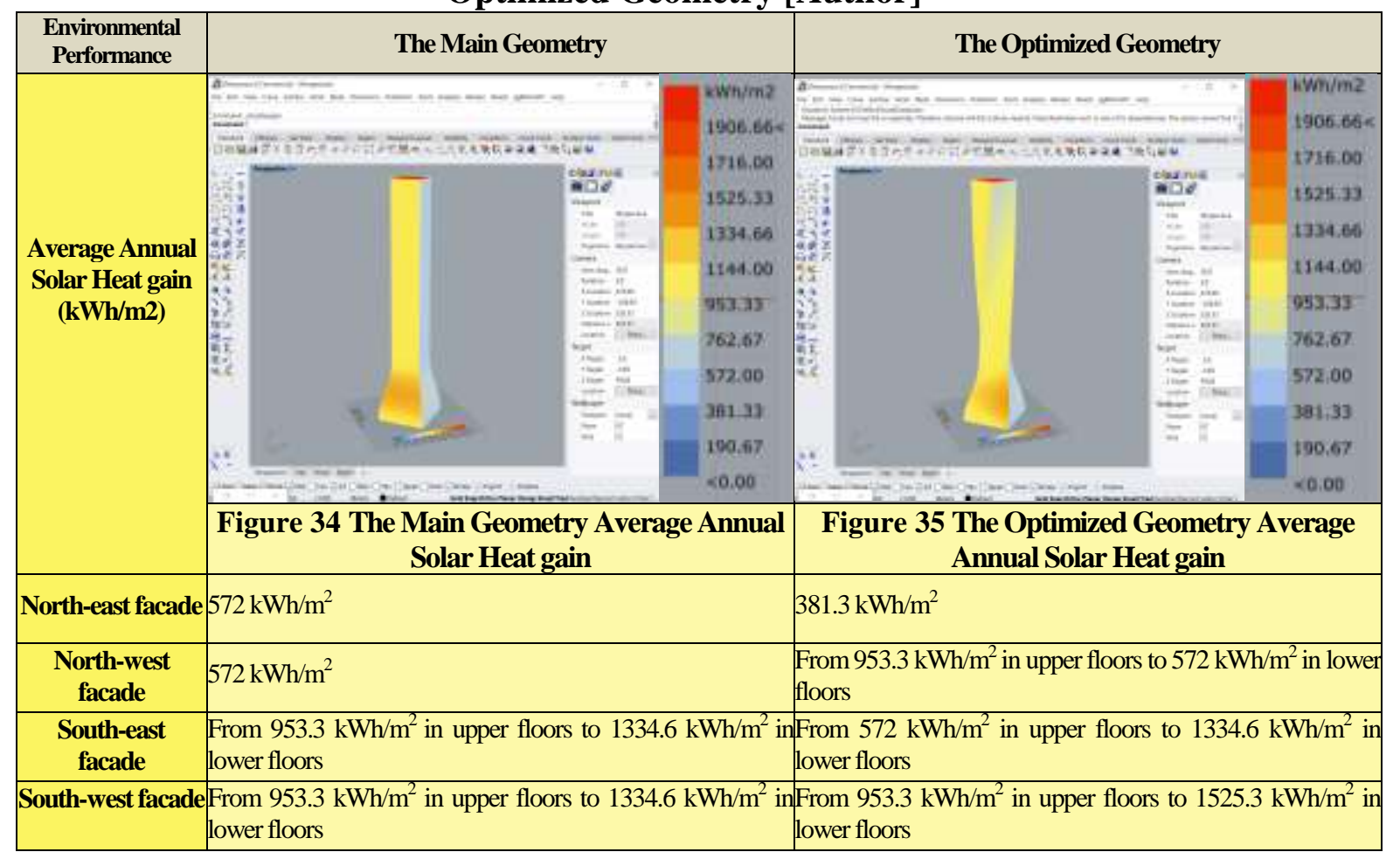




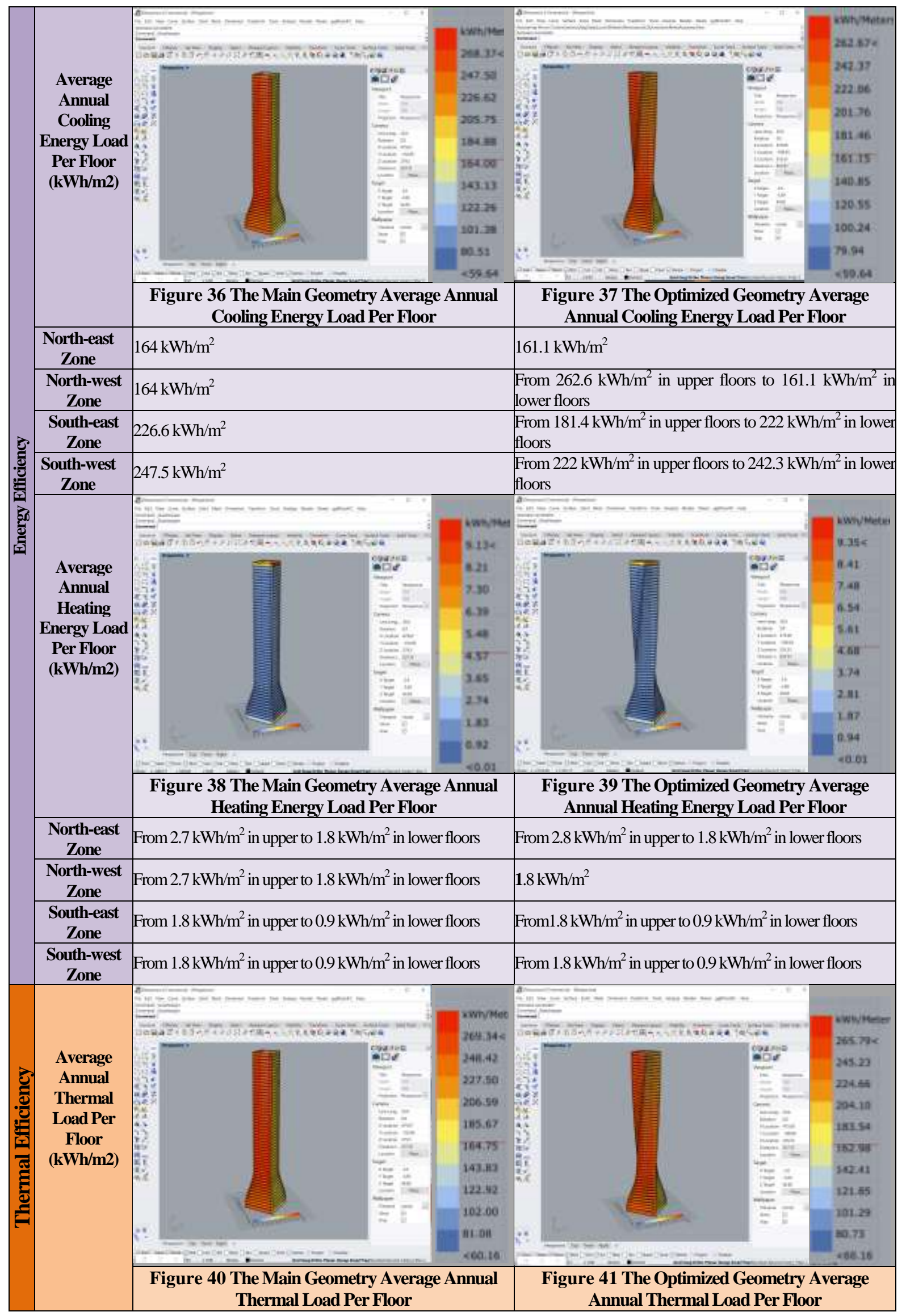




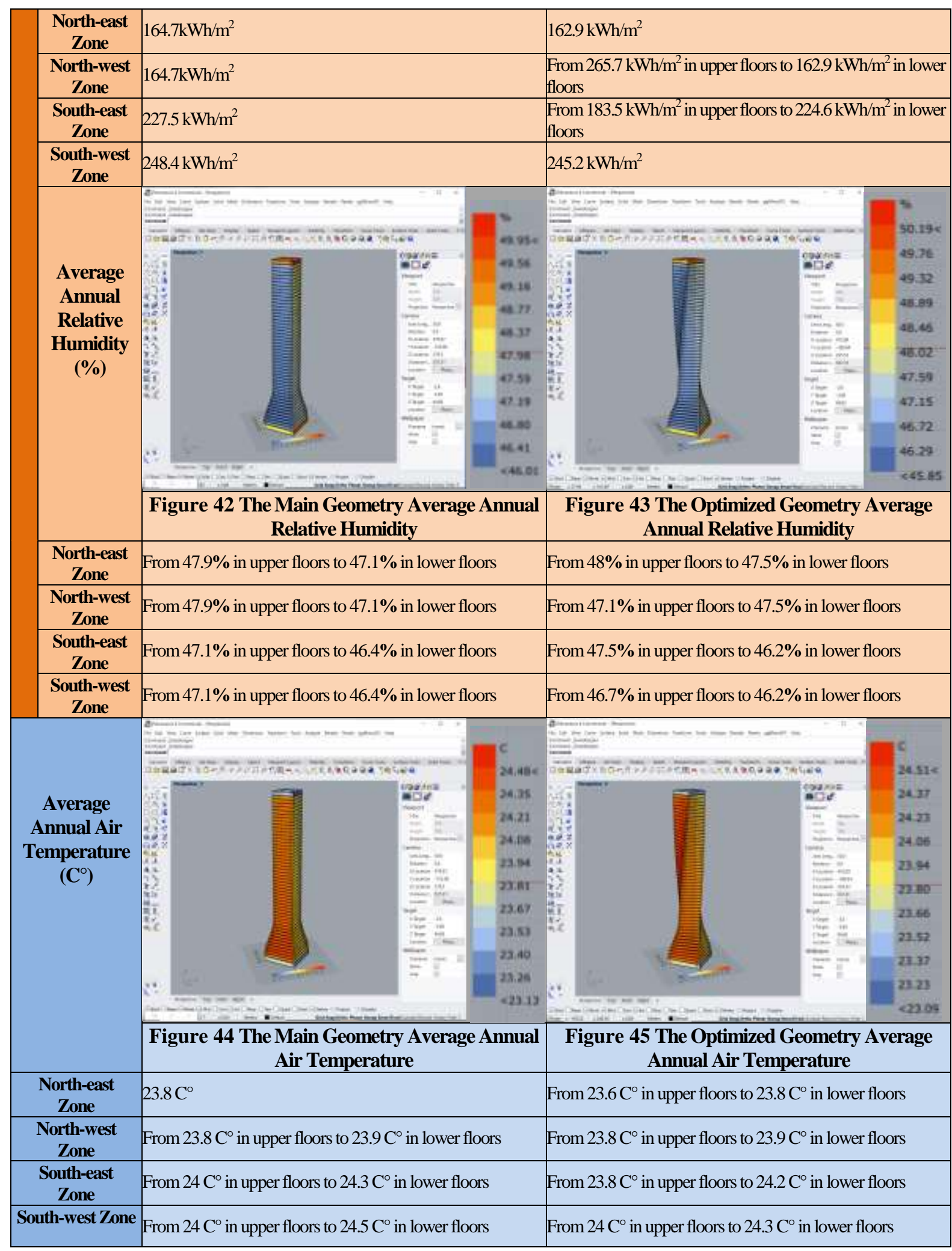




\subsection{Results and Discussion}

The applied study has used parametric design and genetic algorithm as tools to promote building performance. they were used to generate different design alternatives, analysed and filter them, then select the optimal solution with the highest environmental performance, then both the basic and the optimized model were environmentally analysed to verify the optimized solution efficiency, and as a result, by comparing the result of the two models' Energy, Thermal, and Air Temperature simulations, the optimized geometry has shown higher environmental performance efficiency, as:

- The average annual solar heat gain was decreased on the north-east facade by $34 \%$, while on the south-east façade's upper floors by $40 \%$.

- The average annual cooling energy load per floor was decreased in the southeast zones of the upper floors by $20 \%$, and the south-west zones by $10 \%$.

- The average annual heating energy load per floor was decreased in the northwest zones of the upper floors by $34 \%$.

- The average annual Thermal load per floor was decreased in the south-east zones of the upper floors by $19 \%$.

- The Average Annual Air Temperature optimization ratio was low compared to other performances as the tower was modelled to have HVAC system. So, despite that the air temperature ratio is almost the same, the required cooling and heating energy load per floor was decreased by high percentage.

\section{Conclusion and Recommendation}

Accordingly, from the theoretical, analytical, and applied study of utilizing mathematics in promoting environmental performance efficiency, some points were concluded followed by some recommendations.

\subsection{Conclusion}

The present study determined the effect of utilizing mathematics fields as a design tool to promote environmental Performance. Results have shown that;

1. The four branches (Geometry, Parametric, Algorithmic and Topology) are used effectively for promoting environmental performance in contemporary architecture.

2. Both functionality and efficiency factors could be attained by using different mathematical fields.

3. Geometry is mainly used in developing architectural forms by utilizing the properties, proportions, order, scale and transformation of geometrical shape to promote building environmental performance.

4. Generative Algorithmic Design allows designers to code any environmental requirements within the design process, then generate multiple solution, evaluate and filter them many times till reach optimal performative solution.

5. Parametric Design has great potential in generate different geometrical alternatives early in the design process, based on the project's environmental criteria. 
6. Parametric Design and Genetic Algorithmic Design can be integrated to orient the design process to the optimal performative solution early in formfinding process.

7. Parametric Design can integrate with building performance simulations (BPS) to measure the efficiency of the multiple generated solution to facilitate promoting project's environmental efficiency.

8. Topology Optimization techniques are used to find building's optimal topological configurations that have the optimal structural efficiency, and use the least material, within a given design requirements.

9. One or more mathematical branch could be merged and used in same project design process to upgrade the environmental performance efficiency.

10. Mathematics helped in developing creative environmental solutions, and promoting building's efficiency.

\subsection{Recommendations and Future Work}

1. Further studies in this field to explore mathematical branches role in promoting other architectural performance categorization as structural and aesthetical performance.

2. Studying each mathematical branch techniques and methods in promoting building's architectural performance.

3. Architecture Students must be supplied, and learn how to use advanced architecture software that based on mathematics scripting which had a great role increasing their creativity, and abilities, and skills.

\section{References}

1. Choudhary, A., Dogne, N. and Maheshwari, S., "Mathematics and Architecture: Importance of Geometry", National Conference on Advances in Information and Communication Technology (NCAICT), December 2014, P.1, 5.

2. Stavric, M. and Marina, O., "Parametric Modelling for Advanced Architecture", International Journal of Applied Mathematics and Informatics, Issue 1, Volume 5, 2011, P.15.

3. SHI, X., "Performance-based and Performance-driven Architectural Design and Optimization", Frontiers of Architecture and Civil Engineering in China, Vol.4, Issue 4, December 2010, P. 512- 513.

4. Tang, M., Anderson, J., Aksamija, A., and Hodge, M., "Performative Computation-aided Design Optimization", ARCC Journal, Vol. 9 No.1,2012, P.62.

5. Greenberg, M., "Euclidean and Non-Euclidean Geometries Development and History", W. H. Freeman and Company, Third Edition, 1993, P.6.

6. Bellone, T., Fiermonte, F. and Mussio, L., "The Common Evolution of Geometry and Architecture from a Geodetic Point of View", The International Archives of the Photogrammetry, Remote Sensing and Spatial Information Sciences, Volume XLII-5/W1, 2017, P.623.

7. El Iraqi, A., "Form Generation in Architecture Using Tools Based on Evolutionary and Mathematical Functions", Ain Shams University, Master Thesis, 2008, P.36. 
8. Leopold, C., "Geometry Concepts in Architectural Design", 12th international Conference on Geometry and Graphics (ISGG), August 2006, P.1.

9. Burry, J. and Burry, M., "The New Mathematics of Architecture", First Edition, Thames and Hudson, 2010, P. 8-13, 49, 50, 63-65, 93-95, 130- 13, 138, 252, 262, 265.

10. http://www.drmarkliu.com/noneuclidean/ (13/1/2021).

11. Kinayoglu, G., "A reconsideration of The Concept of Architectural Space in The Virtual Realm", Master Thesis, METU | Graduate School of Natural and Applied Sciences, 2007, P. 9, 11, 41- 43.

12. Bobenko, A. and Suris. Y., "Discrete Differential Geometry. Consistency as Integrability", Graduate Studies in Mathematics book, Vol. 98, The American Mathematical Society, 2008, P. 7.

13. Crane, K., and Wardetzky, M., "A Glimpse into Discrete Differential Geometry", Notices of the American Mathematical Society Journal, Vol. 64, Number 10, Nov.2017, P.1153.

14. Gawell, E., "Non-Euclidean Geometry in the Modeling of Contemporary Architectural Forms", Journal of Polish Society for Geometry and Engineering Graphics, Vol. 24, 2013, P. 35- 42.

15. http://www.cplusplus.com/articles/LyTbqMoL/ (13/1/2021).

16. Terzidis, K., "Algorithmic Architecture", Elsevier, First Edition, 2006, P. xii.

17. Dino, I., "Creative Design Exploration by Parametric Generative Systems in Architecture", METU Journal of the Faculty of Architecture, 2012/1, P. 207 - 214.

18. Salim, F. and Burry, J., "Software Openness: Evaluating Parameters of Parametric Modeling Tools to Support Creativity and Multidisciplinary Design Integration", Computational Science and Its Applications Conference ICCSA 2010, Japan, 2010, p.483- 497.

19. Aksamija, A. and Brown, D., "Integration of Parametric Design Methods and Building Performance Simulations for High-Performance Buildings: Methods and Tools", Perkins+Will Research Journal, Vol 10.01, 2018, P.28- 43.

20. https://communities.bentley.com/products/products_generativecomponents/w/gener ative_components_community_wiki/2014/free-form-roof-example (1/8/2020).

21. Peschke, M., "Applying Generative Modelling Tools to Explore Architectural Forms", The Journal of Polish Society for Geometry and Engineering Graphics, Vol.23, 2012, P. 44, 45.

22. https://mathworld.wolfram.com/PretzelTransformation.html (19/11/2020).

23. Hamzehloo, S., Etessam, I., "Performative Design: New Directions in Digital Architectural Design", International Journal of Review in Life Sciences, 2015, P.399.

24. Albayrak, C., "Performative Architecture as a Guideline for Transformation of the Defence Line of Amsterdam", Master Thesis, METU Graduate School of Natural and Applied Sciences, 2011, P. 31- 61.

25. BRE Global Ltd, "BREEAM UK New Construction Non-Domestic Buildings", Feb. 2014, P.5, 59, 75,90, 96, 116-165, 219-257

26. USGBC, "LEED v4 for Building Design and Construction ", Nov.2013, P. 63$105,114,117,122,124,125,126,130,135$. 
27. The Housing and Building National Research Center and the Egyptian Green Building Council, "The Green Pyramid Rating System (GPRS)", First Edition April 2011, P. 13-16, 20-25.

28. https://energyplus.net/ (13/1/2021).

29. https://bigladdersoftware.com/epx/docs/8-2/getting-started/what-is-energyplus.html $(13 / 1 / 2021)$.

30. Trisnawan, D., "Ecotect design simulation on existing building to enhance its energy efficiency", 2nd international Tropical Renewable Energy Conference, 2017, p. 1, 2.

31. Aksamija, A. and Mallasi, Z., "Building Performance Predictions: How Simulations Can Improve Design Decisions", Perkins+Will Research Journal, Vol. 02.02, 2010, P. 14.

32. Jalaei, F., and Jrade, A., “An Automated BIM Model to Conceptually Design, Analyze, Simulate, and Assess Sustainable Building Projects", Journal of Construction Engineering, Volume 2014, 2014, P.11.

33. https://www.radiance-online.org/about (13/11/2019).

34. https://www.equa.se/en/ida-ice/extensions/daylight (28/3/2021).

35. Malkawi, A., "Performance Simulation: Research and Tools", In: Kolarevic, B. amd Malkawi, A. (eds) Performative Architecture Beyond Instrumentality, Spon Press, 2005, P. 87- 89.

36. https://architosh.com/2016/02/trimble-acquires-sefaira-building-performancedesign-software-maker/ (28/3/2021).

37. https://envi.binghamton.edu/index.php/2017/04/17/daylight-analysis-as-design-tool/ $(13 / 1 / 2021)$.

38. https://www.constructionweekonline.com/article-23474-louvre-abu-dhabi-givenpearl-design-certificate $(11 / 11 / 2020)$.

39. https://www.archdaily.com/11602/shell-artechnic-architects\%20(9/11/2020).

40. https://www.thenational.ae/arts-culture/art/one-million-people-visited-louvre-abudhabi-in-its-first-year-we-look-at-what-s-in-store-for-the-next-10-years-1.789988 $(13 / 7 / 2020)$.

41. Imbert F., Frost K.S., Fisher A., Witt A., Tourre V., Koren B. "Concurrent Geometric, Structural and Environmental Design: Louvre Abu Dhabi", In: Hesselgren L., Sharma S., Wallner J., Baldassini N., Bompas P., Raynaud J. (eds) Advances in Architectural Geometry 2012. Springer, 2013, P. 80

42. Garber, R., "BIM Design: Realising the Creative Potential of Building Information Modelling", First Edition, John Wiley \& Sons Ltd, 2014, P. 124, 125.

43. Rian, L. and Sassone, M., "Tree-inspired Dendriforms and Fractal-like Branching Structures in Architecture: A Brief Historical Overview", Frontiers of Architectural Research Journal, Vol. 3, Issue 3, 2014, P. 300, 318.

44. Song, J., Kui, F., and Yan, C., "Model Based on the L-System's Binary Tree Structure and Its Application", Procedia Engineering Journal, Vol. 15, 2011, P.4446-4447.

45. https://divisare.com/projects/323160-serie-architects-the-tote (19/3/2021).

46. Didem Akyol Altun, Bora Örgülü, "Towards a Different Architecture in Cooperation with Nanotechnology and Genetic Science: New Approaches for 
the Present and the Future", The Architecture Research Journal, Volume 4, Number 1B, 2014, P. 3.

47. https://www.fosterandpartners.com/news/archive/2020/01/foster-partners-winscompetition-to-design-alibaba-s-new-offices-in-shanghai/ (6/3/2020).

48. Buelow, P., Falk, A. and Turrin, M., "Optimization of structural form using a genetic algorithm to search associative parametric geometry", International Conference on Structures and Architecture (ICSA), 2010, P. 700.

49. Danhaive, R. and Mueller, C., "Combining parametric modeling and interactive optimization for high-performance and creative structural design", the International Association for Shell and Spatial Structures (IASS) Symposium, 2015, P.1, 2.

50. Hudson, R., Shepherd, P. and Hines, D., "Aviva Stadium: A case study in integrated parametric design", International Journal of Architectural Computing . Vol. 9, June 2011, P. 189- 201.

51. http://omctechnologies.com/projects/aviva-stadium-dublin/ (13/11/2020).

52. Liu, P., Cheng, Y., Citerne, D. and Zhang, L., "The Integrated Smart Design Technologies for Tall Building Structural Design", Cities to Megacities: Shaping Dense Vertical Urbanism Conference, 2016, P. 705 - 710.

53. Shao, W., "China Zun: Shaping the Future Skyline of Beijing”, CTBUH 2014 Shanghai Conference Proceedings, 2014, P. 180.

54. Liu, P., Luo, N., Whitlock, R., and Lei, L., "Case Study: China Zun Tower, Beijing", CTBUH Journal 2014, Issue III, 2014, P. 18.

55. Cheng, Y., Liu, P., and Wong, K., "A vessel for commerce", The Arup Journal, 2019, Issue 2, P. 20- 27.

56. Naboni, R. and Paoletti, I., "Handbook of Research on Form and Morphogenesis in Modern Architectural Book - Chapter 4: Architectural Morphogenesis Through Topology Optimization", IGI Global. 2018, P. 69-73, 89.

57. Dapogny, C., Faure, A. Michailidis, G., Allaire, G., Couvelas, A. and Estevez, R., "Geometric Constraints for Shape and Topology Optimization in Architectural Design", Computational Mechanics Journal, June 2017, Vol. 59, Issue 6, , P. 933-936.

58. Januszkiewicz, K. and Banachowicz, M., "Nonlinear Shaping Architecture Designed with Using Evolutionary Structural Optimization Tools", IOP Conference Series: Materials Science and Engineering, Volume 245, 2017, P. 3 - 8. 